\title{
ESTADO E POLÍTICAS EDUCACIONAIS: QUESTÕES EPISTEMOLÓGICAS
}

\section{EL ESTADO Y LAS POLÍTICAS EDUCATIVAS: CUESTIONES EPISTEMOLÓGICAS}

\section{THE STATE AND EDUCATIONAL POLICIES: EPISTEMOLOGICAL ISSUES}

DOI: http://dx.doi.org/10.9771/gmed.v11i3.33603

Regis Argüelles da Costa ${ }^{1}$

Resumo: O objetivo deste estudo é elaborar um programa de pesquisa das políticas educacionais que dê conta da totalidade histórica. Partirá das reflexões sobre o Estado ampliado e a hegemonia política de classes no capitalismo, bem como sobre o papel dos intelectuais e dos aparelhos privados de hegemonia (APHs) na questão educacional. Um programa de pesquisa de políticas educacionais norteado por esses princípios deve (1) mapear e analisar os APHs e seus intelectuais orgânicos que atuam no setor; (2) analisar as principais estratégias de sistematização e divulgação de parâmetros para as políticas educacionais; e (3) compreender as estratégias utilizadas pelos diferentes sujeitos coletivos em sua atuação e em sua influência no Estado estrito.

Palavras-chave: Políticas educacionais; Estado; Teoria.

Resumen: El objetivo de este estudio es elaborar un programa de investigación de políticas educativas que tenga en cuenta la totalidad histórica. Comenzará con reflexiones sobre el Estado ampliado y la hegemonía política de las clases en el capitalismo, así como sobre el papel de los intelectuales y los aparatos privados de hegemonía (APHs) en la cuestión educativa. Un programa de investigación de políticas educativas guiado por estos principios debe (1) mapear y analizar los APHs y sus intelectuales orgánicos que operan en el sector; (2) analizar las principales estrategias de sistematización y divulgación de parámetros para políticas educativas; y (3) comprender las estrategias utilizadas por los diferentes sujetos colectivos en su desempeño y su influencia en el Estado estricto.

Palabras clave: Políticas educativas; Estado; Teoría

Abstract: The aim of this study is to elaborate a research program of educational policies that accounts for the historical totality. It will start from reflections on the extended State and the political hegemony of classes in capitalism, as well as on the role of intellectuals and hegemonic private apparatuses (HPAs) in the educational question. An educational policy research program guided by these principles should (1) map and analyze the HPAs and their organic intellectuals operating in the sector; (2) analyze the main strategies of systematization and disclosure of parameters for educational policies; and (3) understand the strategies used by the different collective subjects in their performance and their influence on the strict state.

Keywords: Educational policies; State; Theory.

\section{Introdução}

A resposta dada pela burguesia à crise de acumulação que se deflagrou nos primeiros anos da década de 1970 teve implicações profundas no mundo do trabalho e, consequentemente, nos processos de formação humana. Os avanços tecnológicos representados pela microinformática, pela robótica e pela genética foram associados a processos de reorganização do trabalho no chão de fábrica, no que se condicionou chamar de toyotismo.

Tais determinações exigiram, por sua vez, um trabalhador de novo tipo: flexível, criativo, dotado de capacidade de abstração, capaz de trabalhar em grupo e acumular tarefas, com sólida formação 
geral associada a um conhecimento amplo dos processos internos de sua empresa ou local de trabalho (FRIGOTTOO, 2010).

A atualização da formação para o trabalho foi acompanhada do aumento exponencial da concorrência pelos postos de melhores remunerações. O cenário estimulou a corrida em busca de mais formação, a partir das exigências crescentes do mercado de trabalho, o que tem levado muitas escolas particulares a diversificarem seus currículos, oferecendo programas de ampliação do dia letivo às famílias.

Por outro lado, o desemprego e a pobreza estrutural, além da maciça entrada das mulheres no mercado formal de trabalho, também produtos dessa nova forma de realização do capital, trouxeram novas determinações para a conformação de grande parte da classe trabalhadora, impactando nas formas e nas trajetórias de escolarização. Portanto, podemos afirmar que as transformações na morfologia do trabalho (ANTUNES, 2005) vêm reforçar o caráter da educação de massas enquanto arena de intricadas questões de hegemonia.

Uma das grandes expressões dessa luta tem se dado em torno das políticas para a educação básica no Brasil. A literatura aponta que o campo educacional foi sacudido por vagas contrarreformistas dirigidas por setores do empresariado brasileiro (LEHER, 2010), direcionadas a todos os níveis e modalidades, a partir dos anos de 1990. Movimentos similares ocorreram em diversos países da América Latina (CASASSUS, 2001).

Em relação ao caso brasileiro, Frigotto (2010) nos chama atenção para alguns dos efeitos das contrarreformas educacionais, destacando a concepção redutora de currículo, baseada na aquisição de competências em língua portuguesa e matemática, e a incorporação de modelos de gestão empresarial pela escola, com ênfase na descentralização, nos cumprimentos de metas e nas parcerias com o setor privado. Trata-se, sobretudo, da definição externa e antidemocrática sobre um dos aspectos mais essenciais do trabalho docente - o que se ensina e se avalia - e também sobre o modelo de gestão escolar. Em outras palavras, um movimento que visa a uma ampla intervenção nos sistemas públicos de educação.

Procurando se distanciar de perspectivas idealistas sobre o Estado e a sociedade civil, este artigo busca apresentar uma concepção teórico-metodológica calcada no materialismo histórico dialético para a análise das políticas educacionais contemporâneas. Nesse sentido, entendemos que a compreensão efetiva dos sentidos dominantes que são atribuídos à educação por setores do empresariado brasileiro torna-se possível através de um modelo de abordagem que considera o Estado a condensação das relações sociais em determinada formação política (MENDONÇA, 2007).

Acreditamos que tal abordagem do problema do Estado nos encaminha ao esclarecimento de questões fundamentais para a discussão contemporânea sobre a atuação de setores do empresariado em direção às políticas educacionais. Tais como: quem são os intelectuais orgânicos e quais são os sujeitos coletivos responsáveis pela elaboração, pela sistematização e pela divulgação da agenda empresarial de ampliação da jornada escolar? Como se estrutura a rede de atuação desses sujeitos coletivos na sociedade civil, levando em conta as adesões e as tensões intraclasse? Quais são as principais estratégias de 
sistematização e divulgação na sociedade civil e política, pelos sujeitos coletivos e seus intelectuais ligados ao empresariado, de parâmetros para as políticas educacionais?

Dividimos o artigo em quatro seções, a contar com esta Introdução. Na próxima seção, apontaremos algumas das tendências contemporâneas de análise das políticas educacionais que reificam o papel do Estado, tratando-o enquanto sujeito ou "ator institucional" no processo de desenvolvimento de uma política educacional.

Na seção seguinte, As contribuições de Gramsci e Poulantzas: por uma abordagem crítica do Estado, apresentaremos uma abordagem marxista das questões do Estado, explorando alguns conceitos desses dois autores. Por último, discutiremos as possibilidades que esse arsenal teórico-metodológico nos abre para o estudo de políticas educacionais contemporâneas.

\section{Política enquanto narrativa e o problema do poder}

Parece-nos bastante evidente que o debate epistemológico no campo das políticas educacionais acompanhou, em larga medida, a inflexão pós-estruturalista das ciências humanas como um todo. Ela apontou, em linhas gerais, para a necessidade de superação de modelos marxistas e/ou estruturalistas de análise da realidade social, por suas fragilidades no trato de questões ligadas às subjetividades ou pela ausência de uma reflexão epistemológica voltada aos múltiplos processos de dominação e exercício de poder, os quais transcenderiam as determinações de classe social produzidas na dinâmica de realização do capital (FOUCAULT, 1979). Em relação específica ao marxismo, os pós-estruturalistas em geral passaram a tratá-lo como um paradigma ultrapassado, à medida que a sociedade capitalista criticada por Marx e Engels já havia sido superada com o advento da Terceira Revolução Industrial e o fim da Guerra Fria.

De acordo com Wood (2003, p. 220), o então chamado mundo "pós-moderno" se caracterizaria pela "fragmentação crescente, diversificação de relações e experiências sociais, pluralidade de estilos de vida, multiplicação de identidades pessoais". A teoria social deveria dar conta dessas novas dinâmicas que aparentavam dissolver as estruturas calcadas no modelo keynesiano-fordista, produzindo uma epistéme que representasse a classe não a partir de uma análise das práticas materiais dos sujeitos, mas a partir do signo em si, da linguagem. No que ficou conhecido como "virada cultural", as narrativas e os símbolos passaram a representar a(s) realidade(s) per si, transformando a classe social em mais uma metáfora para determinados jogos linguísticos (EBERT; ZAVARZADEH, 2008).

Pleiteando uma abordagem que dê conta da complexidade social da sociedade capitalista do século passado, o pós-estruturalismo parte da premissa de que as relações de dominação não seguem um fluxo determinado e previsível, cujo polo de irradiação seria, muitas vezes, representado pelo aparelho de Estado e pelo conjunto dos grandes conglomerados econômicos, os quais determinariam, por sua vez, o que deve ser absorvido pelos estratos inferiores.

Para os pós-estruturalistas, o poder configura-se como uma rede conflituosa de discursos dotados de "vontades de verdade" ou saberes, os quais materializam práticas no cotidiano das 
instituições e aparelhos que compõem a base do tecido social. O poder deve ser percebido, portanto, como uma rede amorfa de discursos que se chocam em topos distintos, produzindo, consolidando e resistindo às múltiplas práticas de controle e repressão das subjetividades (FOUCAULT, 1979).

As metodologias idealizadas para o enfretamento da análise da rede de poder buscaram desenvolver formas de capturar e codificar as distintas produções de práticas derivadas de discursos. O caráter amplo explicitado pelas premissas discutidas acima originou abordagens metodológicas que entendem as políticas a partir de categorias como contexto, texto, processo e discurso, dando especial atenção à microprodução de sentidos catalisada pela ação prática dos atores que participam de determinada política. Com isso, espera-se superar as linearidades e os modelos tecnicistas que foram hegemônicos durante os anos de 1970 e 1980 (MAINARDES; FERREIRA; TELLO, 2011).

A ênfase dada à fluidez das múltiplas narrativas enquanto substrato de análise promoveu o obscurecimento das relações materiais de classe, não tendo muito a dizer sobre as relações desiguais de poder quanto à mercadoria-trabalho, que atravessam constantemente todos os poros do tecido social. Nessa vaga de potencialização das narrativas e das identidades, as relações de dominação resguardadas e reforçadas pelo Estado capitalista e suas políticas são também eclipsadas, tornando-o um objeto fora de moda (MENDONÇA, 2007) ou mais um tropo do discurso moldado a partir de uma complexa e amorfa combinação de identidades e diferenças.

Um exemplo de aplicação dessas premissas epistemológicas está em Beech (2009), em um estudo que trata da internacionalização das políticas educacionais na América Latina, comparando as reformas dos anos de 1990 no Brasil, na Argentina e no Uruguai. O autor adere a um modelo de dupla conceptualização das políticas, que são vistas enquanto texto e enquanto discurso, a partir do entendimento de que existe um hiato entre a formulação e a execução de qualquer política pública. $\mathrm{O}$ momento da formulação das propostas educacionais pelas agências multilaterais seria caracterizado pela produção de discursos com o objetivo de manter as relações de poder.

Considerando que os discursos favorecem certos significados, enquanto inibem o surgimento de outros, sua funcionalidade estaria na conformação das possibilidades de interpretação dos sentidos da política. Contudo, a política é também um texto, e dessa forma está aberta a uma variada gama de interpretações pelos agentes responsáveis por colocá-la em prática. Essa característica chama atenção aos diversos contextos de implementação das políticas, o que explicaria as diferenças entre Brasil, Argentina e Chile na aplicação da agenda educacional formulada pela Organização das Nações Unidas para a Educação, a Ciência e a Cultura (UNESCO), pelo Banco Mundial (BM) e pela Organização para a Cooperação e Desenvolvimento Econômico (OCDE).

A ênfase em "captar o poder em suas extremidades, em suas últimas ramificações, lá onde ele se torna capilar" (FOUCAULT, 1979, p. 182) estimulou decerto uma criatividade metodológica e de recorte objetal, alargando as possibilidades investigativas do pesquisador. Todavia, esse empirismo vem provocando em alguns pesquisadores considerações sobre o poder que vão de encontro àquelas premissas de multiplicidade espacial e morfológica que configuram sua distribuição na contemporaneidade. 
De acordo com Mainardes, Ferreira e Tello (2011), Stephen J. Ball vem investindo numa investigação de políticas educacionais que privilegia o processo histórico, as mudanças na economia e o papel do Estado. Em um trabalho que se propõe a analisar a rede de relações entre fundações sociais do empresariado, intelectuais e o Estado estrito, formada ao redor do Movimento pela Base Nacional Comum (MBNC), Avelar e Ball (2019) apontam para a problemática do aparelhamento do Estado pelos agentes individuais e coletivos da "nova filantropia empresarial" em sua relação com as políticas educacionais.

Ainda que mantendo conclusões que preservam o caráter pós-estruturalista, ao afirmar, por exemplo, que as redes de relações provocadas pelas organizações que atuaram no MBNC produzem novas "topologias de política" (AVELAR; BALL, 2019, p. 72), os autores chamam atenção para o papel de relevo das finanças na determinação dos métodos, conteúdos e objetivos da educação no Brasil, a partir da ocupação de postos-chave no Ministério da Educação e no Conselho Nacional de Educação.

Seja como for, esse modelo conceptual se baseia em argumentos que opõem frontalmente os recortes macro àqueles que valorizam os "microcontextos", avaliando que os primeiros deixam escapar elementos fundamentais das políticas ao desvalorizarem a participação dos agentes durante todo o processo. Em consequência, faz-se necessária a produção de todo um quadro teórico-metodológico que dê conta da dimensão focalizada da política, em oposição às teorias "estadocêntricas", inspiradas no marxismo.

As afirmações da teoria centrada no Estado são construídas com base em uma série de oposições, difíceis de ser defendidas e, em última instância, inúteis, na medida em que dificultam o diálogo. Teóricos que adotam uma abordagem estadocêntrica afirmam estar preocupados com "questões mais amplas", ou seja, com o macrocontexto. Eles identificam "coerência" e "consistência". Aqueles que tratam das microinvestigações, por outro lado, estão interessados nos "detalhes". O trabalho deles envolve o "acúmulo de informações" e a "coleta de descrições ricas". Longe de olhar propriedades duradouras, encontram "improviso", "acaso" e "confusão". (POWER, 2011, p. 71)

A contradição fundamental que essa oposição lógica deixa escapar repousa justamente na valorização heurística de todas as "microdiferenças" que, ao mesmo tempo, desqualifica as condições de extrema diferença nas práticas materiais como "oposições inúteis", cuja função é apenas de "dificultar o diálogo". Por detrás desse holofote epistêmico, obcecado com os detalhes e as descontinuidades, esconde-se toda uma lógica sistêmica fundamentada nas diferenças materiais de classe, que atravessam dramaticamente seja a dimensão macro, seja a micro.

Derivada desse esquecimento das diferenças de classe é a concepção do Estado como espaço do autoritarismo, das decisões de cima para baixo, das interdições do discurso. Estamos diante, para situarmos o debate no pensamento gramsciano, da hipervalorização do momento coercitivo do Estado.

Por outro lado, a sociedade civil é definida a partir de suas condições propícias para o estabelecimento de pontes discursivas, o que favoreceria a construção e a consolidação democrática dos consensos. Como sublinha Mendonça (2007), essa noção "asséptica” da sociedade civil destaca sua condição de espaço potencialmente fora do Estado, onde o exercício da associação voluntária e plural 
possui predominância, em contraste com a coerção que impregna as relações sociais determinadas pelo aparelho estatal.

Dessa feita, o "novo" conceito de "sociedade civil" - e por extensão o de Estado ganha roupagem nova, celebrando a pluralidade e a diversidade, contidas num sem número de novas instituições e relações sociais de tipos, os mais diversos, tradicionalmente não contempladas pelo marxismo, transmutando-se numa "noção guarda-chuva", que a tudo é capaz de abrigar, desde ONGs até entidades filantrópicas. (MENDONÇA, 2007, p. 10)

A operacionalização dessas concepções idealizadas do Estado e da sociedade civil tem se mostrado funcional na divulgação dos interesses de setores do empresariado em direção às políticas educacionais. Um exemplo bastante ilustrativo dessa funcionalidade conceitual aparece na agenda empresarial para ampliação da jornada da escola pública, tema que desfruta de importante ressonância no debate educacional desde a experiência dos CIEP's nos anos de 1980.

De acordo com Cavaliere (2009), nos últimos anos, um modelo de organização da ampliação da jornada escolar ganhou considerável relevo. Esse modelo avalia que a escola é uma instituição enrijecida, que perdeu a capacidade de diálogo com os seus alunos e as suas famílias. A nova sociedade do conhecimento exige modelos institucionais flexíveis, capazes de atender às demandas contemporâneas por formação, e a "velha escola do século XX" já não mais responde adequadamente a essas demandas.

A ampliação da jornada escolar deve, então, abandonar a organização centrada na "escola de tempo integral" - tal quais os CIEPs e outras experiências dos anos 80 - e adotar, em seu lugar, o modelo organizacional que a autora denomina "aluno de tempo integral". De acordo com esse ponto de vista, a jornada ampliada do aluno deve ser compartilhada entre as escolas e as organizações da sociedade civil, à medida que estas últimas estariam mais capacitadas a oferecer oportunidades de aprendizagem diversificadas, de acordo com as necessidades e potencialidades da comunidade.

A divulgação sistemática dessa agenda, proposta ao Brasil pelo Banco Mundial em 1987², aqui, ganhou corpo a partir dos anos 2000, com participação relevante do Centro de Estudos e Pesquisas em Educação Comunitária (CENPEC), uma Organização Não Governamental (ONG) paulista financiada pelo Banco Itaú. A partir de sua capacidade de diálogo, bem como de sua capacidade de atrair colaboradores dos mais diversos níveis para a pauta da jornada escolar ampliada, importantes frações do capital, interessadas em interferir nas políticas educacionais foram fundamentais na idealização do Programa Mais Educação, política federal de ampliação da jornada para a educação básica (COSTA, 2018), e da Meta de número 6 do Plano Nacional de Educação, que prevê ampliação de matrículas em tempo integral, em vez de escolas de tempo integral.

Ao fim e ao cabo, a justificativa teórica para a ampliação da jornada escolar acontecer fora da escola, junto às organizações da sociedade civil, repousa na oposição entre o Estado autoritário e padronizador, pertencente ao campo das "estruturas", e a sociedade civil enquanto reino do diálogo e do consenso. 
A escola pública é, dessa maneira, definida como uma instituição anacrônica, presa a práticas já ultrapassadas, incapaz de perceber a realidade para além de seus muros. Carrega, portanto, a chaga estadocêntrica da administração dos serviços públicos, e é por isso que não consegue mais dialogar com a sua audiência. Por outro lado, as organizações da sociedade possuiriam, tradicionalmente, maior capilaridade e flexibilidade no contato com a comunidade, sendo assim mais "antenadas" aos anseios de crianças e jovens em idade escolar.

Ao associar o modelo de escola pública ao Estado autoritário e, ao mesmo tempo, apontar para a sociedade civil organizada como solução para a questão da ampliação da jornada escolar, os teóricos de certa agenda escondem muito mais do que parecem mostrar. A ocupação de postos-chave no aparelho do Estado por representantes dos sujeitos coletivos ligados às frações de classe do empresariado parece ser uma prática comum e relevante, pois permite a implementação da sua agenda.

Tal fenômeno merece uma contraposição teórico-metodológica que o aborde de acordo com a categoria marxiana da totalidade e que dê conta, portanto, da dinâmica das lutas de classe que ocorrem tanto na sociedade política quanto na sociedade civil. A partir dessa perspectiva, é possível analisar, por exemplo, o porquê de organizações da sociedade civil ligadas ao capital financeiro, tais como o CENPEC, voltarem seus interesses para as políticas educacionais. Quais são suas estratégias no processo de aproximação do aparelho do Estado, no sentido de pautar as reformas da educação pública? Veremos algumas possibilidades de respostas a essas questões na seção a seguir.

\section{As contribuições de Gramsci e Poulantzas: por uma abordagem crítica do Estado e das políticas educacionais}

As reflexões gramscianas sobre o poder do e no Estado capitalista de massas atualizaram a teoria política marxista. De acordo com Coutinho (1999), os conceitos de Gramsci “ampliam” a concepção de Estado, ao entendê-lo como um organismo composto por dois grandes planos superestruturais: Estado-coerção stricto sensu, ou sociedade política, que detém o monopólio legal dos aparelhos de repressão e violência (burocracia executiva, judiciária e legislativa, e o aparato policialmilitar); e a sociedade civil, espaço de atuação das organizações privadas, como as Igrejas, os partidos políticos, as escolas, os sindicatos e meios de organização material da cultura (jornais, revistas, editoras, meios de comunicação de massa), entre outras. Esses dois planos são espaços do desenrolar das lutas de classes, cada um com suas devidas especificidades.

A ampliação das relações organizativas e conectivas dos Estados modernos acompanhou o cenário de expansão colonial europeu após 1870. Sobre essa modificação, o pensador sardo diz o seguinte:

Ocorre na arte política o que ocorre na arte militar: a guerra de movimento torna-se cada vez mais guerra de posição; e pode-se dizer que um Estado vence uma guerra quando a prepara de modo minucioso e técnico no tempo de paz. A estrutura maciça das democracias modernas, seja como organizações estatais, seja como conjunto de associações na vida civil, constitui para a arte política algo similar às "trincheiras" e às fortificações permanentes da frente de combate na guerra de posição: faz com que 
seja apenas "parcial" o elemento do movimento que antes constituía "toda" a guerra, etc. (GRAMSCI, 2012, p. 24, grifos nossos)

Dessa maneira, a luta política passou a incorporar a problemática da hegemonia civil em uma formação social capitalista, na qual o Estado e seus aparelhos desempenham importantes papéis, combinando coerção e consenso em caráter ampliado e complexo. Em Gramsci, as lutas em um cenário de hegemonia burguesa precisam considerar a atuação do conjunto dos aparelhos privados de hegemonia (APHs), a partir do estudo das relações de força que tensionam as classes fundamentais e suas frações. O modelo gramsciano privilegia, portanto, o caráter relacional presente na composição da estrutura de dominação política - o Estado - do capitalismo monopolista, relação esta que responde aos níveis políticos da luta de classes, nacionais e supranacionais.

A mediação de interesses entre as classes fundamentais e as frações da classe dominante, no Estado ampliado, implica precisamente o problema da organização da hegemonia, pois a manutenção do bloco de poder incorpora o desenvolvimento de algumas ações que garantam algum grau de consenso junto aos dominados. Assim, a força repressiva do aparelho estatal só precisaria ser utilizada em situações extremas - justamente durante as "crises de hegemonia", quando nenhuma fração é capaz de dirigir politicamente as classes em luta.

O processo de convencimento dirigente pressupõe, naturalmente, recuos e compromissos com os interesses das classes subordinadas. Portanto, a ampliação do Estado dá conta das estratégias lançadas pela fração de classe dominante (por exemplo, o capital financeiro), a fim de construir a unidade em relação à sua própria classe, bem como de estabelecer vínculos com os dominados, transformandose, dessa maneira, em classe dirigente. Longe de ser um simples instrumento externo às relações sociais, o Estado articula-se com essas relações de consenso encouraçadas de coerção (BUCI-GLUCKSMANN, 1977; COUTINHO, 2011).

Além da vasta discussão provocada pela teoria de Estado gramsciana, ${ }^{3}$ a qual não é possível cobrir neste espaço, interessa-nos o relevo dado pelo autor italiano à necessidade, nas sociedades democrático-burguesas, de "formação de sujeitos políticos de massa" (COUTINHO, 1999, p. 125). Nesses termos, fica claro o papel educador do Estado na produção do "homem coletivo" ao adaptar a “civilização’ e a moralidade das massas às necessidades de desenvolvimento contínuo do aparato econômico de produção" (GRAMSCI, 2012, p. 23), algo como o aumento do componente mercantil da relação educacional formal. É o momento de construção do consenso que apresenta o problema de como a pressão educativa deverá ser aplicada em cada indivíduo, "para obter seu consenso e sua colaboração, transformando necessidade e coerção em 'liberdade”' (GRAMSCI, 2012, p. 23).4

A educação equivale, para Gramsci, às operações fundamentais de hegemonia (BUT'TIGIEG, 2003). A tarefa de educar para determinado modelo de sociabilidade, apesar de não se restringir apenas à escolarização formal, faz da escola uma das instituições estratégicas para a construção de um projeto hegemônico de poder.

O ensino formal deve ter por meta a preparação de intelectuais dos mais diversos níveis, de acordo com as determinadas necessidades econômico-políticas do Estado. O papel dos intelectuais no 
contexto da socialização da política se reveste aí de novas características, que também interferem no direito à educação e na função da escola, que é o espaço de sua formação. Cabe aos intelectuais de novo tipo exercer funções de hegemonia social e do governo político, necessárias para a manutenção da ordem consentida e para a garantia da produção em moldes capitalistas.

Nesse sentido, ampliaram-se as funções da escola de massas, fenômeno cujas raízes não se encontram simplesmente no processo de industrialização, ${ }^{5}$ à medida que também responde às "necessidades políticas do grupo fundamental dominante" (GRAMSCI, 2000, p. 22). Quanto mais diferenciados os ramos e níveis da escola, prossegue nosso autor, mais complexa seria a formação social de um determinado Estado. Entretanto, o modelo de reprodução da vida social sob o capitalismo implica, fundamentalmente, a coexistência de uma escola para os dominantes e outra para os dominados, cujas formações respondem às necessidades de formação de quadros especializados nas áreas de reprodução do capital, além de um vasto exército industrial de reserva.

Dessa maneira, a ampliação do conceito de Estado corresponde à ampliação do conceito de intelectual nos Cadernos do Cárcere. Sua capacidade heurística está justamente na conexão que o intelectual estabelece entre o terreno da produção e o Estado ampliado; são os diversos níveis de intelectuais orgânicos, organizados em aparelhos privados de hegemonia, que assumem as funções de sistematização e divulgação, na sociedade civil e política, dos interesses das frações de classe que representam. Aqui, esse conceito se reveste de grande importância, à medida que instiga a análise da relação entre ONGs, Organizações da Sociedade Civil de Interesse Público (OSCIPs), Organizações Sociais (OS) e think tanks do empresariado, seus agentes sociais - os intelectuais orgânicos -, o aparelho de Estado e as políticas públicas para a educação.

As pesquisas de Mendonça $(1997,2007)$ sobre a questão agrária no Brasil foram pioneiras na metodologia de aplicação dos conceitos gramscianos de Estado ampliado, aparelhos privados de hegemonia e intelectual orgânico. Seus trabalhos demonstram o estabelecimento, desde o final do século XIX, de aparelhos privados de hegemonia que funcionavam como porta-vozes das frações agrárias, atuando simultaneamente na sociedade civil e política. Acreditamos que dinâmicas semelhantes ocorrem no campo das políticas educacionais, dada a relevância do campo educacional na luta política de classes.

As características do Estado capitalista discutidas por Poulantzas $(1977,1985)$ enriquecem a concepção crítica sobre as políticas educacionais, sublinhado aspectos das contradições entre as classes fundamentais e suas frações, que são acomodadas no aparato estrito de Estado. A complexificação crescente do capitalismo contemporâneo, especialmente nas formações sociais que apresentam uma inserção dependente na realização global do capital, vem trazendo renovados desafios para a dominação política de classes.

A concretização da agenda política de classe em lei, e sua devida observação e aderência aos diversos níveis do aparelho de Estado são elementos cruciais no exercício da hegemonia, e caracterizamse como um espaço no qual a resistência também se faz possível. Essa característica se dá devido à autonomia relativa que o Estado possui frente às lutas de classes, autonomia que, por sua vez, é condição sine qua non para a manutenção do poder de classe. 
Poulantzas (1985) caracterizou o Estado como elemento capaz de condensar as relações de classe e que, portanto, é atravessado por diversas contradições correspondentes àquelas relações. Entendidas como instrumentos de manutenção da hegemonia de uma classe sobre as demais, as políticas públicas encerram, em parte, estratégias de conservação do estado de coisas. Mas a necessidade de estabelecimento do consenso, situação que permite a efetiva dominação, implica uma série de concessões que, de alguma maneira, garantem alguma margem de manobra política às classes subordinadas.

Essa abordagem nos convida a uma apreciação teórico-metodológica do Estado ampliado que está mais interessada nas relações entre sociedade política e sociedade civil do que em estabelecer as distinções entre os dois planos, tal como a que associa mecanicamente o Estado estrito à coerção e a sociedade civil ao consenso. A perspectiva relacional do par conceitual é, conforme Bianchi (2008, p. 177), a linha adotada pela reflexão gramsciana sobre o conceito de Estado ampliado, "na qual não existe uma rígida divisão de tarefas entre as duas esferas e, pelo contrário, tem-se em vista dar conta das novas tarefas hegemônicas próprias do Estado”.

Outro desdobramento importante da perspectiva relacional está em evitar pensar os pares conceituais Estado estrito e sociedade civil, coerção e consenso, ditadura e hegemonia como elementos de uma operação algébrica de soma zero, o que sugere uma dinâmica combinatória mais adequada ao movimento da história.

Considerar a autonomia relativa das instituições e de suas políticas em relação às classes sociais indica, em primeiro lugar, a possibilidade de abordagem da escola e do sistema educativo como um espaço privilegiado de manifestações das lutas entre dominantes e dominados, que conserva uma historicidade própria. No que tange ao presente trabalho, tal consideração do movimento das lutas favorece, no nosso entender, a fluidez e o direcionamento de hipóteses ao objeto de estudo. Acreditamos que essa perspectiva revitaliza a utilização do conceito de lutas de classe, pois libera todo o potencial interpretativo contido na análise crítica das correlações de força, livrando-o do engessamento teóricometodológico e de possíveis mecanicismos.

Mas, sublinha Poulantzas (1985), tal autonomia não significa a presença de um poder próprio do Estado, distinto do poder de classe; sua especificidade vem da relação contraditória que a instituição mantém com as estruturas, ou seja, com os diversos níveis da luta de classes. Dada a defasagem que caracteriza esses níveis e a pluralidade dos centros de poder existentes, é possível estabelecer distinções hierárquicas entre os centros de poder, de acordo com suas posições em relação às estruturas e à correlação de forças entre as classes de uma formação social. Tal distinção é útil, pois indica que as relações de poder entre as classes rebatem de maneira diferenciada nos múltiplos centros de poder, sendo que, em alguns, as condições de luta política são menos desfavoráveis aos dominados do que a outros.

Por isso, entendemos ser de fundamental importância, no estabelecimento de uma crítica consistente às políticas educacionais propostas pelo empresariado para a escola pública, a consideração da escola enquanto um centro de poder. É um espaço, portanto, permeável às resistências elaboradas pelos aparelhos contra-hegemônicos, ligados às frações da classe trabalhadora. 
O que queremos sublinhar, portanto, é que o aparelho de estado é também espaço de construção da hegemonia, caracterizado por uma correlação de forças específica, dada a sua autonomia relativa em relação às classes sociais. Essa especificidade do aparelho de Estado pode ou não ser favorável à construção da hegemonia, portanto, a análise da implementação e da gestão da agenda empresarial para a escola pública em ambos os planos estruturais (sociedade política + sociedade civil), dentro desse referencial crítico, é incontornável.

Acreditamos que as reflexões desenvolvidas aqui possibilitam uma série de questões sobre as políticas educacionais contemporâneas, as quais, acreditamos, têm muito a contribuir para o debate no campo. Em primeiro lugar, quais são as razões concretas que dirigem a intervenção das classes dominantes na política da educação, considerando a relação desta com o econômico, o político e o ideológico? Trata-se apenas de uma nova fase do saque ao fundo público educacional ou podemos também considerar as determinações ético-políticas na composição da agenda empresarial para a educação pública brasileira?

Quais são as frações que dirigem a intervenção no campo educacional e, logo, quais aparelhos privados de hegemonia e intelectuais que as representam no Estado ampliado? Como se configura essa rede? Quais são seus polos de dominância e suas estratégicas de cooptação/associação? Ao abordar o Estado não como sujeito histórico, mas sim como produto da história, podemos desvelar relações que estão ocultas na maioria dos estudos sobre política e educação, expressas pelas questões acima.

Para além do espírito crítico que nos guia, enquanto sujeitos políticos, em nossa luta por uma educação efetivamente transformadora das relações entre as classes, precisamos tomar o problema da educação no capitalismo dependente pela raiz, se quisermos compreender e combater o projeto da classe dominante para a educação pública do Brasil, projeto este em pleno curso.

\section{Considerações finais}

À guisa de conclusão, entendemos que um programa de pesquisa das políticas educacionais norteado pelos princípios discutidos na seção anterior deve se pautar pelas diretrizes descritas a seguir.

Mapear e analisar os APHs e seus intelectuais orgânicos que atuam no campo educacional, focalizando possíveis conexões e tensões intraclasses e entre as classes fundamentais, expressas por essa rede. O mapeamento deve respeitar a hierarquia de poder que organiza essa rede de sujeitos coletivos, além de enfatizar os diferentes papéis que cada um deles cumpre na rede, papéis esses que se relacionam diretamente com essa hierarquia de poder. Nesse sentido, ao partir de um APH qualquer, deve-se ter no horizonte que ele integra um nó de uma ampla rede de sujeitos políticos que, por sua vez, organiza e conecta o campo educacional segundo os interesses do bloco de poder.

Analisar, pelos APHs e seus intelectuais, as principais estratégias de sistematização e divulgação de parâmetros para as políticas educacionais. Gramsci (2000) chama a atenção para mecanismos de "repetição" que podem ser utilizados no trabalho educativo-formativo de destruição do que é "velho". É preciso ter atenção tanto para a forma, ou seja, quais são as estratégias de divulgação preferenciais 
(anúncios na mídia, seminários, premiações, sítio na internet, redes sociais), quanto para o conteúdo: saber o que é divulgado em cada espaço da sociedade civil e política nos permite entender que alianças se quer formar e quais são as razões que orientam essas alianças. Da mesma importância é analisar as possíveis tensões intraclasses e entre as classes fundamentais que a divulgação da agenda provoca.

Compreender a atuação e a influência desses sujeitos coletivos no Estado estrito, considerando a complexidade de instituições que compõem o aparelho público educacional. Para tanto, deve-se levar em conta a especificidade da posição do Estado capitalista de massas em relação às classes fundamentais e suas frações, discutida neste trabalho, que é a da autonomia relativa. Além disso, devem ser considerados os diferentes níveis do aparelho de Estado ocupados pelos centros de poder e o trabalho organizativo e conectivo dos intelectuais nesses espaços. Isso permite que observemos o Estado estrito em sua relação de unidade-distinção com a sociedade civil e que entendamos concretamente as políticas educacionais como a condensação dos arranjos instáveis produzidos nessas duas esferas de poder.

\section{Referências}

ANTUNES, Ricardo. O caracol e sua concha: ensaios sobre a nova morfologia do trabalho. São Paulo: Boitempo, 2005.

AVELAR, Marina; BALL, Stephen John. Mapping new philanthropy and the heterarchical state: The Mobilization for the National Learning Standards in Brazil. International Journal of Educational Development, v. 64, p. 65-73, 2019.

BEECH, Jason. A internacionalização das políticas educativas na América Latina. Currículo sem Fronteiras, v. 9, n. 2, p. 32-50, jul./dez. 2009.

BUCI-GLUCKSMANN, Christine. Sobre o conceito de crise de Estado e sua história. In: POULANTZAS, Nicos (org.). O Estado em crise. Rio de Janeiro: Edições Graal, 1977.

BIANCHI, Álvaro. O laboratório de Gramsci: filosofia, história e política. São Paulo: Alameda, 2008.

BUTTIGIEG, Joseph. Educação e hegemonia. In: COUTINHO, Carlos Nelson; TEIXEIRA, Andréa de Paula (org.). Ler Gramsci, entender a realidade. Rio de Janeiro: Civilização Brasileira, 2003. p. 3950 .

CASASSUS, Juan. A reforma educacional na América latina no contexto de globalização. Cadernos de Pesquisa, n. 114, p. 7-28, nov. 2001.

CAVALIERE, Ana Maria. Escolas de tempo integral versus alunos em tempo integral. Em Aberto, Brasília, v. 22, n. 80, p. 51-63, 2009.

COSTA, Regis Argüelles da. Ampliação da jornada escolar e o Terceiro Setor: a atuação do CENPEC. Educação \& Realidade, Porto Alegre, v. 43, n. 2, p. 401-414, abr./jun. 2018.

COUTINHO, Carlos Nelson. De Rousseau a Gramsci: ensaios de teoria política. São Paulo: Boitempo, 2011.

COUTINHO, Carlos Nelson. Gramsci: um estudo sobre seu pensamento político. Rio de Janeiro: Civilização Brasileira, 1999.

EBERT, Teresa; ZAVARZADEH, Mas'ud. Class in culture. Boulder, CO: Paradigm Publishers, 2008. FOUCAULT, Michel. A microfísica do poder. Rio de Janeiro: Edições Graal, 1979.

FRIGOTTO, Gaudêncio. Educação e formação humana: ajuste neoconservador e alternativa democrática. In: Educação e a crise do capitalismo real. São Paulo: Cortez, 2010. 
GRAMSCI, Antonio. Cadernos do cárcere, volume 2: Os intelectuais - o princípio educativo Jornalismo. Rio de Janeiro: Civilização Brasileira, 2000.

GRAMSCI, Antonio. Cadernos do cárcere, volume 3: Maquiavel - Notas sobre o Estado e a política. Rio de Janeiro: Civilização Brasileira, 2012.

GRAMSCI, Antonio. Selections from the Prison Notebooks. New York: International Publishers, 2010.

LEHER, Roberto. 25 anos de educação pública: notas para um balanço do período. In: GUIMARÃES, Cátia (org.). Trabalho, educação e saúde: 25 anos de formação politécnica no SUS. Rio de Janeiro: EPSJV, 2010.

MAINARDES, Jefferson; FERREIRA, Márcia dos Santos; TELLO, César. Análise de políticas: fundamentos e principais debates teórico-metodológicos. In: BALL, Stephen John; MAINARDES, Jefferson. Políticas educacionais: questões e dilemas. São Paulo: Cortez, 2011.

MENDONÇA, Sonia Regina de. Estado e políticas públicas: considerações político-conceituais. Outros tempos, v. 1 esp., p. 1-12, 2007.

MENDONÇA, Sonia Regina de. O ruralismo brasileiro (1888-1931). São Paulo: HUCITEC, 1997.

NETTO, João Paulo. Capitalismo monopolista e serviço social. São Paulo: Cortez, 2007.

POULANTZAS, Nicos. O Estado, o poder, o socialismo. Rio de Janeiro: Edições Graal, 1985.

POULANTZAS, Nicos. Poder político e classes sociais. São Paulo: Martins Fontes, 1977.

POWER, Sally. O detalhe e o macrocontexto: o uso da teoria do Estado para explicar práticas e políticas educacionais. In: BALL, Stephen John; MAINARDES, Jefferson. Políticas educacionais: questões e dilemas. São Paulo: Cortez, 2011.

THE WORLD BANK. Memorandum of the President of the International Bank for reconstruction and development and the International Finance Corporation to the Executive Directors on a Country Assistance Strategy of the World Bank Group for the Federative Republic of Brazil. Brazil: Federative Republic of Brazil, 1997. Disponível em: http://documents.worldbank.org/curated/en/902681468017467876/pdf/multi-page.pdf. Acesso em: 12 set. 2019.

WOOD, Ellen Meiksins. Democracia contra capitalismo: a renovação do materialismo-histórico. São Paulo: Boitempo, 2003.

\section{Notas:}

1 Professor Adjunto do Departamento de Fundamentos Pedagógicos - FEUFF Orcid: https://orcid.org/0000-0001-61034659 Email: rarguelles@gmail.com

2 Ver The World Bank (1997).

3 Uma excelente discussão sobre o tema, com atenção especial para a transformação de um conceito de tradição revolucionária, a sociedade civil, em álibi para o capitalismo, encontra-se no artigo de E. Wood, Sociedade civil e política de identidade (WOOD, 2003, p. 205-225).

${ }^{4}$ Em relação ao problema da hegemonia no Estado ampliado, Gramsci (2010, p. 207, tradução nossa) afirma que "um grupo social pode e, de fato, deve já exercer 'liderança' (ou seja, ser hegemônico) antes de ganhar poder governamental (essa é, de fato, uma das principais condições para ganhar tal poder)".

5 O processo que mais se relaciona com a ampliação das funções internas do Estado é a monopolização de capitais, mais acentuada no último quartel do século XIX. "Na idade do monopólio, ademais da preservação das condições externas da produção capitalista, a intervenção estatal incide na organização e na dinâmica econômicas desde dentro, e de forma contínua e sistemática. Mais exatamente, no capitalismo monopolista, as funções políticas do Estado imbricam-se organicamente com suas funções econômicas" (NETTO, 2007, p. 25, grifos do autor). 